\title{
Comparison of Differences in Eastern and Western Ethical Values
}

\author{
Maoyun Hu \\ Soochow University, School of Politics and Public Administration Jiangsu Suzhou 215000
}

Keywords: comparison of differences in ethical values between East and West

\begin{abstract}
In today's increasingly globalized trend, the links and exchanges between countries have become more frequent. Under such realistic conditions, differences in ethical values have received wide attention from all walks of life. Only by truly standing on a macroscopic perspective, taking me as the main, using it for me, taking the essence, and abandoning it as a starting point, can we better break through the various negative effects brought about by the differences in the ethical values between East and West, and realize the prosperity and common advancement of culture and value. Based on the reality of China's international competition and communication, this paper makes a comparative analysis of the differences between the East and the West in order to provide a reference for promoting China's international cultural process and realizing China's international development.
\end{abstract}

\section{The East and West ethical values}

Ethical value is an important spiritual manifestation of a nation or region in the process of long-term development. Through the in-depth analysis and research on the connotation and form of ethical values, one can understand the cultural tradition, ideology and overall quality of a country. There are many differences between traditional Western cultural and traditional Chinese culture. There are still great differences in the process of understanding the connotations and concepts of human nature, but in the process of long-term development, among the developed countries in the West. The culture of propaganda has always dominated the existing process of human civilization, and theory of original evil of human nature is particularly important and crucial. In contrast, for our country's educational thoughts and ethics, we pay great attention to these important themes of benevolence and benevolence. With the continuous development of globalization, the cultural exchange and communication mechanism between China and the West is becoming more and more perfect, and the frequency of exchanges and interactions is getting higher and higher. Under such realistic conditions, China's traditional culture is hard to avoid being subjected to foreign exchanges. The impact and influence of culture, in order to truly promote the embodiment of ethical values and enrichment and diversification, China must compare and analyze the differences between Chinese and Western ethical values, so as to truly seek common ground while reserving differences and common development.

\section{The comparative analysis of the ethical value of the East and the West}

If we analyze the ethical values of East and West from a macro perspective, it is not difficult to find that there are certain differences in the concept of fairness and efficiency. When the western scholars analyze the efficiency of traditional public administration, they directly regard it as the highest level standard in the whole process of public administration. Through effective cost control, they can truly achieve the maximum output and ensure that they can obtain more economic benefits. With the acceleration of human civilization, the new public administration emerges at the right moment. The new public administration criticizes the traditional public administration deeply, no longer focuses on the mechanical efficiency, but focuses on the effective combination between public interests and individual values, positively reflects a kind of social efficiency. The new public management is based on the deficiencies and defects in the traditional public administration and the dilemma of the effective breakthrough efficiency. Thus it can be seen that western utilitarian more 
focuses on the fair pay and equal rights, the government can better reflect the most people's happiness and interests, realize social justice and social justice, while at the same time this fair is likely to affect the interests of others, but still meets the requirement of the efficiency of justice this important.

In contrast, China strictly follows the relevant requirements of the ethical value of fair efficiency, constantly promotes the improvement and establishment of public policies, and takes justice and fairness as the important value orientation and basis of administrative ethics. In the process of promoting the development of public administration, the disinterested motives in administration are studied deeply, and the negative effects of special interests and thoughts are excluded as far as possible. Secondly, in the process of institutionalized interest arrangement, China actively takes a macro perspective, takes improving the image of social justice of the government as the entry point, carries forward excellent capacity values from the perspective of fairness and justice, and better promotes the effective play of public administration. From this, it can be seen that the theory of fairness and efficiency can truly promote the narrowing of the gap between the rich and the poor, point out the road and direction for the further development of social equity, and ensure the stable construction of society. However, if we focus only on the pursuit of fairness and ignore the further development of society, it will be difficult to truly reflect the important basis of efficiency priority and improve people's quality of life and living standards, which is especially crucial for the construction of socialist market economy. If carry on the analysis from another angle, then it is not difficult to find that, in the process of the pursuit of efficiency, one-sided pursuit can only lead to social justice is restricted by the severe, unable to truly achieve the effective defense of moral behavior, eventually leading to many local governments focus only on efficiency when promoting local economic construction, but neglects the maintenance of the public interest.

Secondly, in promoting the construction of socialist market economy, China has combined efficiency priority with balance fairness, adopted the distribution mode of socialist market economy operation, actively promoted the effective practice of this concept, and achieved good economic benefits. However, there are also serious social contradictions in China, and the wealth gap is increasing. The public sector faces many difficulties and obstacles in practical work, and perceptions of seniority and performance are still very serious, which cannot truly promote the full play of the role of excellent talents. In order to guarantee more advantages in the fierce market competition, China must analyze and think about this deficiency carefully.

Finally, most of the ethical values are mainly oriented towards fairness in western developed countries. While the justice of efficiency and the justice of fairness are based on individualism, which can only protect the legitimate interests of bourgeois individuals and cannot truly promote the further improvement of social equity, which is different from China's collectivism and civic values. In the process of promoting social equity and social justice, China takes collectivism as the entry point to truly realize the common interests and common prosperity of the whole society. In addition to adhering to socialist market economy, it is also necessary to actively learn from the relevant advantages and functions of western ethical values, and flexibly apply and adjust them on the basis of absorption, so as to better realize the effective play of China's internal force.

\section{Comparative analysis of eastern and western views of ethical responsibility}

Western countries tend to define subjective responsibility from a negative perspective, and at the same time make active use of different rules and law in institutional design to strengthen the control of individuals, among which objective responsibility is critical. In order to truly guarantee individuals to strengthen the norms of behaviors, western developed countries began to integrate capacity training and morality education into the existing laws and regulations education system to clarify the subject value of administrative personnel, so the rule of law is relatively strong. By contrast, China attaches great importance to the understanding and respect of human nature, positively focuses on the improvement of personal quality and late moral education and influence, to ensure that administrative staff truly realize the role and value of individual work and establish good sense of social responsibility and subjectivity with internal control. Provide more basis and 
assistant function for the effective play of my political system function. Among them, the objective responsibility of the administrative personnel is very important. In the process of the establishment of bureaucracy in western developed countries, technical, impersonal and formal rationality are the main factors. and can only operate in a mechanized mode. Overcoming the differences between different management individuals to a greater extent. China pays great attention to the mobilization of individual subjective initiative, giving full play to individual role and value, and realizing individual individual growth and development. However, different management individuals will bring about greater differences and it is easier to form "one emperor and one courtier". In addition, when establishing and improving relevant management systems and administrative rules and regulations, China takes the social public interest as the basis to define the game rules of the market,

and on this basis to safeguard the public rights and interests of the society and realize the comprehensive improvement of the quality and level of social management.

\section{Conclusion}

Different regions and countries in the national psychology, geographic space and historical tradition, cultural customs, there are many differences, the differences of the ethical values of all, in addition to need to pay attention to the comprehensive economic strength of ascension, and also need to be based on the essence of the capacity value differences exist, negative influence brought by the positive response to these differences, the realization of the real essence and discard the dregs, in the process of mutual communication and interaction to promote mutually beneficial and win-win and common development. How on the premise of human value differences between east and west to achieve effective communication and interaction between the two sides, is each national and the national important issues to consider, but what is really aware of the differences, and on differences to seek common ground while putting aside differences, can better avoid the internationalization process of all kinds of negative influence.

\section{References}

[1] Ke Xuemin. Comparative analysis of differences between Chinese and western administrative ethics values [J]. Journal of liaoning university of administration, 2008, 10(11):7-8.

[2] Zhou Fangyou. Historical evolution and comparative study of Chinese and Japanese administrative values [D]. Xiangtan university, 2012.

[3] Michelle - S - DE - vries king sentenced to tin, MichielS. DeVries, etc. In the public administration values and virtues: a comparative study perspective [M]. Renmin university of China publishing hous me, 2014.

[4] Chen Karen. On the differences in core values between China and the west from Chinese and western idioms [J]. Journal of wuyi university, 2016, 35(2):22-25.

[5] Zhou Huitao, Sun junyi. Western administrative ethics: evolution in the perspective of public administration theory [J]. Journal of pingxiang university, 2006(1):16-20. 